\title{
Factors Associated and Response to Needle Stick Injuries among Nursing Officers in District General Hospitals of Sri Lanka
}

\author{
Yapa M. M. Priyangani ${ }^{1}$, Gamaralalage S. K. Dharmaratne ${ }^{2} \&$ Sathasivam Sridharan $^{3}$ \\ ${ }^{1}$ District General Hospital, Kegalle, Sri Lanka \\ ${ }^{2}$ National Hospital for Respiratory Diseases, Welisara, Colombo, Sri Lanka \\ ${ }^{3}$ Directorate Healthcare Quality and Safety, Castle Street, Colombo, Sri Lanka \\ Correspondence: Yapa Mudiyanselage Mihiri Priyangani, Deputy Director, District General Hospital, Kegalle, Sri \\ Lanka.
}

Received: January 27, 2017 Accepted: February 20, 2017 Online Published: May 29, 2017

doi:10.5539/gjhs.v9n8p107 URL: https://doi.org/10.5539/gjhs.v9n8p107

\begin{abstract}
Introduction: This study was carried out to find out the existing prevalence rates of the Needle Stick Injuries (NSIs) among nursing officers in Sri Lankan health delivery system and to identify the factors associated with NSIs including the level of knowledge, attitude and practice on prevention.

Methods: A descriptive cross sectional study was conducted in three District General Hospitals. Five routine working units identified from each hospital. Proportional allocations were made with a final step of simple random sampling to select the sample. Self- administered questionnaire was used for data collection.

Results: Response rate was $95 \%$ and the prevalence of NSIs was $43 \%$. IV cannulation was the most risky procedure (51\%). Re-capping was seen in $24 \%$ of the exposed group. Medical wards accounted for $78 \%$ of the NSIs. There was a significant difference in NSIs seen in maturity in age $(p=0.015)$ and increase working experience $(p=0.044)$ but no difference was found with increased work load (no. of patients seen per day, $p=0.765$, increase number of working hours per week, $p=0.204)$ and participation in in-service training programs $(p=0.592)$. Pre exposure Hepatitis B immunization was seen in only $64 \%$. A significant $49 \%$ did not report the injury and the main reason was assumed less risk (46\%).

Conclusion: Prevalence of NSIs was still high and ignorance and neglect are the main causes. Health education and in-service training should be mainly directed at inculcating knowledge into practice and changing attitudes towards safe practices. Hepatitis B immunization should be provided as early as possible.
\end{abstract}

Keywords: Needle-stick, Injuries, Nurses, prevalence, knowledge, attitude, practice, Sri Lanka

\section{Introduction}

Exposure to blood and body fluids is a preventable health hazard among health care workers (HCW). This risk is extensively studied in developed countries. It is not well documented and explored in developing countries where the exposure is much more common (Peuss-Ustan, Rapiti, \& Hutin, 2005)

These exposures put HCWs at risk of acquiring more than 20 different blood born infections. Most important pathogens are hepatitis $\mathrm{B}$ virus (HBV), hepatitis $\mathrm{C}$ virus (HCV) and Human Immuno-Deficiency virus (HIV). In addition it can also transmit measles, infectious mononucleosis, diphtheria, herpes, tuberculosis, brucellosis and many other diseases (United States, Centers for Disease Control and Prevention, 2003).

Studies on prevalence and factors associated with NSIs have helped to build awareness and take precautions and reduce the incidence of these injuries (Wickwer, Jung, Allwinn, et al., 2008). A safety program conducted at Toronto East General Hospital showed $80 \%$ reduction in such injuries within one year (US, CDCP, 2003). Similar results were seen at University hospital of Tokyo by reducing the injuries from 19.8 to $5.5 \%{ }^{3}$.

According to Occupational Health and Safety Administration in United States (US, CDCP, 2003) without immunization and post exposure prophylaxis the chance of transmission of HBV after NSI is $6-30 \%$ and $\mathrm{HCV}$ is $0-7 \%$. The chance of transmission of HIV is $0.3-0.45 \%$. The psychological impact of NSIs mainly anxiety and emotional distress is also significant (Lee \& Bottleman, 2005; Wicker et al., 2008). 
Some countries provide legal protection to HCWs to prevent exposure to blood and body fluids through NSIs. Namely, in United States the "Needle stick Safety and Prevention Act" brought forward in November 2000 ensured availability of safety devices to all staff by the employers (United States, Labour Department, 2001). In Germany, the "Technical Rule 250-Biological Agents in Health Care and Welfare Facilities" (Technische Regeln für Biologische ArbeitsstoVe 2006) ensured the safety of the health care personnel (Wicker et al., 2008)).

The economic impact of NSIs had been emphasized in a comparative study done on data from Italy, Spain, France, Germany, United Kingdom and United States (Saita et al., 2010). The economic burden was also identified by World Health Organization two decades ago (World Health Organization [WHO], 1994). It explained to the member countries "that access to occupational health services should be ensured for all workers of the world, irrespective of age, sex, nationality, occupation, type of employment, or size or location of the workplace." The different resource constraints in many countries were identified as a barrier to fulfill this task (Deussom, Jaskiewicz, Adams, \& Tulenko, 2012).

Hard work of many researchers on studying NSIs mainly aimed at discovering strategies to prevent such injuries. Both organizational and technical strategies were identified as important. Using safety devices ${ }^{3}$, minimizing the invasive procedures, training, improving knowledge on prevalence and risk factors for NSIs, vaccination against preventable diseases and make availability of post exposure prophylaxis were identified as the main strategies to prevent such diseases. Risk for infection, illness, disability and death from acute hepatitis, chronic hepatitis, hepatocellular carcinoma and AIDS were identified as the main serious consequences (Wicker et al., 2008).

Worldwide 35 million HCWs are at risk of getting a needle stick injury in a given year through a contaminated needle or other sharp device (Deisenhammer, Randon, Nowak, \& Reichert, 2012). Estimated two million NSIs occur worldwide each year and 40-70\% of them are unreported (WHO, 2003). In 2000, WHO predicted 16000 Hepatitis C Virus infections (HCV), 66000 Hepatitis B Virus infections (HBV) and 1000 Human Immunodeficiency Virus infections (HIV) might occur due to NSIs. More than $90 \%$ of these infections were predicted to be occurring in developing countries where the unnecessary injections were common.

In Sri Lanka the prevalence of HBV is $0.29 \%-2.5 \%$, HCV is $0.56 \%-0.97 \%$ and $\mathrm{HIV}$ is $0.1 \%{ }^{9}$. Recent reports on country prevalence on HIV infections have indicated Sri Lanka as a low prevalence but high risk country (Ministry of Sri Lanka [MOHSL], 2011).

The main objective of this study was to assess the prevalence, factors associated and response to accidental needle stick injuries among nursing officers working in Kegalle, Gampaha and Nuwara-Eliya District General Hospitals in Sri Lanka. The specific objectives were,

1). To determine the prevalence of needle stick injuries among nursing officers in Kegalle, Gampaha and Nuwara-Eliya District General Hospitals.

2). To assess the knowledge, attitude and practice about prevention of needle stick injuries among nursing officers.

3). To determine the prevalence of needle stick injuries in relation to selected factors; work place, work load, training and experience of nursing officers

\section{Materials and Methodology}

Prospective cross sectional study was carried out. Positive cases were identified as nursing officers sustaining NSIs with in their service period. Respondents who had experienced NSIs more than one occasion were asked to give the frequency in relation to time. Further analysis on factors associated with NSIs was done on last exposed NSI.

Sri Lanka has 1076 curative health care institutions. These institutions are divided into six different main categories according to services they provide and the bed strength ${ }^{11}$. The administrative network of Sri Lanka divides the country into nine provinces and twenty five districts. Eighteen District General hospitals (DGH) are located in 17 districts. Teaching and provincial general hospitals provide the service in other 8 districts.

Three DGHs in three different provinces, Kegalle, bed strength 759 in Sabaragamuwa province, Gampaha, bed strength 772 in western province and Nuwara-Eliya bed strength 426 in Central province were purposively selected for the study. Five routine working units were identified and proportional allocations were made to each unit. The final selection of the candidates was done by simple random sampling taking the duty roster as the sampling frame.

The study Period was March 2014 to September 2014. Sample size was determined by power. At 95\% level of confidence and 5\% margin of error, a minimum sample of 384 was needed for this study (Lawanga \& Lamesho, 1991). A $10 \%$ non-respondent rate was added to this number giving 422 sample size altogether. 422 questionnaires 
were distributed in three hospitals and 401 participants responded voluntarily giving a response rate of $95 \%$.

The questionnaire was prepared for self-administration. The questions were prepared with a group of experts in the field, Administrative Nursing Officers (Matron), Nursing Officers In-charge in the Infection Control Units, Consultant Anaesthesiologist, Consultant Microbiologist and Consultant Medical Administrators. The questionnaire was pre tested and test-retested in one week with the same group of participants to assess the reliability. Needle stick injury (NSI) for this study was defined as " any cut or prick to the respondents by sharps such as hypodermic needles, blood collection needles, iv cannulas, suture needles, winged needle iv sets and needles used to connect parts of the delivery systems which previously used on a patient and sustained within the hospital premises".

Total of 66 questions were included under the format of simple tick box with few open ended questions. Data were collected on socio-demographic factors, number of NSIs, factors contributed to NSIs, knowledge, attitude and practice on preventing needle stick injuries, work place, selected facilities provided and work load, practice of reporting after NSI, basic post exposure management, post exposure blood testing, post exposure prophylaxis and hepatitis B immunization.

The Statistical Package for Social Sciences (SPSS) version 21.0 (SPSS 21.0; SPSS Inc., Chicago, IL, USA) was used to analyze the data.

Data were analyzed with frequency distributions, cross tabulations, Chi-square test and independent sample t-test.

Chi-square test was used to analyze the associations between NSI and institution of work, having in-service training and post basic qualifications. The t-test was used to analyze the difference between two groups (group that experienced NSI and the group that did not experience NSI) in relation to age, average working hours per week, average number of patients given care per day and average duration of years of working experience.

Results generated from the analysis on various aspects of NSIs were then grouped and presented in tables for interpretation and discussion.

Proposal was approved by the board of study at Post Graduate Institute of Medicine, University of Colombo (PGIM). Ethical clearance was obtained from the Ethical Review Committee, Faculty of medicine, University of Colombo.

\section{Results}

This study was conducted in three District General Hospitals with similar capacity to treat people and with nursing officers possessing similar basic nursing qualification backgrounds. Nursing officers from five treatment units were selected from each hospital. Descriptive statistics including frequency tables, cross tabulation, chi-square test and independent sample t-test was used to analyze the data and SPSS version 21 software package was used as the tool to statistical analysis.

The distribution of study population in the three different hospitals and their unit at work is shown in the Table 1. Most of the participants were (27.7\%) from the medical wards.

Table 1. Distribution of study population according to place of work $(\mathrm{N}=401)$

\begin{tabular}{lll}
\hline Category & & $\mathrm{n}(\%)$ \\
\hline Institution & Kegalle & $189(47.1)$ \\
& Gampaha & $143(33.4)$ \\
& Nuwara-Eliya & $78(19.5)$ \\
\hline Unit at Work & Medical & $111(27.7)$ \\
& Surgical & $93(23.2)$ \\
& Paediatric & $60(15.0)$ \\
& OPD & $56(14.0)$ \\
& Gyn \& Obs & $81(20.2)$ \\
\hline
\end{tabular}

The Table 2 shows the demographic and social characteristics of the study population and their working experience. Majority were female and married. More than $85 \%$ of the population had the working experience of more than five 
years in clinical work after three years of basic training.

Table 2. Demographic characteristics and the work experience of the study population $(\mathrm{N}=401)$

\begin{tabular}{lll}
\hline & Category & $\mathrm{n}(\%)$ \\
\hline Age & Up to 30 years & $51(12.7)$ \\
& $31-40$ years & $(18345.6)$ \\
& $41-50$ years & $108(26.9)$ \\
& More than 50 years & $59(14.7)$ \\
\hline Gender & Female & $396(98.8)$ \\
& Male & $5(1.2)$ \\
\hline Marital Status & Married & $388(96.8)$ \\
& Unmarried & $13(3.2)$ \\
\hline Work Experience & $0-5$ years & $56(14.0)$ \\
& $6-10$ years & $130(32.4)$ \\
& $10-15$ years & $57(14.2)$ \\
& $16-20$ years & $50(12.5)$ \\
& More than 20 years & $108(26.9)$ \\
\hline
\end{tabular}

\subsection{Prevalence of NSIS}

Table 3 shows the prevalence of NSIs in the total population and in individual institutions. The overall prevalence rate was $43.1 \%$ but there was no significant relationship between experiencing NSIs and the institution at work $\left(\mathrm{X}^{2}\right.$ $[2, \mathrm{~N}=173]=3.584, \mathrm{p}=0.167)$

Table 3. Prevalence of NSI in the total population and in separate institutions

\begin{tabular}{llll}
\hline & Category & $\mathrm{n}(\%)$ & Statistical test \\
\hline Experience in NSI & Yes & $173(43.1)$ & \\
& No & $228(56.9)$ & \\
\hline Total & $401(100)$ & Chi-square test \\
\hline Institution & Kegalle & $76(43.9)$ & Test value $=3.584$ \\
& Gampaha & $56(32.4)$ & \\
& Nuwara Eliya & $41(23.7)$ & $\mathrm{p}=0.167$ \\
\hline
\end{tabular}

Table 4 below shows the total number of NSIs experienced by the nurses during their career and how many NSIs they had during the last year. Out of 173 nursing officers who experienced NSIs $4.6 \%$ had claimed they had more than 4 NSIs during their career. During the year before 61 (35.2\%) individuals had experienced NSIs.

Table 4. Prevalence of NSI during the career

\begin{tabular}{lll}
\hline & Category & $\mathrm{n}(\%)$ \\
\hline Frequency of NSI in career & 1 time & $67(38.7)$ \\
& 2 times & $49(28.3)$ \\
3 times & $23(13.3)$ \\
& 4 times & $12(6.9)$ \\
\hline
\end{tabular}




\begin{tabular}{|c|c|c|}
\hline & More than 4 times & $8(4.6)$ \\
\hline & No idea & $14(8.1)$ \\
\hline & total & $173(100)$ \\
\hline \multirow[t]{7}{*}{ Frequency of NSI in relation with time } & During last year & $61(20.2)$ \\
\hline & 2 years back & $35(15.0)$ \\
\hline & 3 years back & $26(4.0)$ \\
\hline & 4 years back & $7(7.5)$ \\
\hline & 5 years back & $13(17.9)$ \\
\hline & More than 5 years back & $31(35.3)$ \\
\hline & Total & $173(100)$ \\
\hline \multirow[t]{7}{*}{ Frequency of NSI during the last year } & 1 time & $31(7.7)$ \\
\hline & 2 times & $18(4.7)$ \\
\hline & 3 times & $3(0.7)$ \\
\hline & 4 times & $4(1.0)$ \\
\hline & More than 4 times & $1(0.2)$ \\
\hline & No idea & $4(1.0)$ \\
\hline & Total & $61(100)$ \\
\hline
\end{tabular}

Table 5 shows analysis of NSIs in relation to clinical procedure they performed. Iv cannulation (29.5\%) showed highest risk of getting NSIs followed by finger prick blood sampling (19.7\%). Further analysis on which part of the procedure caused the NSIs revealed while withdrawing the needle from the patient or the cannula had caused most of the injuries $(38.7 \%)$.

Table 5. Prevalence of NSI in relation with clinical procedure $(\mathrm{N}=173)$

\begin{tabular}{lll}
\hline & Category & $\mathrm{n}(\%)$ \\
\hline During which procedure you experience NSI & Iv injection & $23(13.3)$ \\
& IM injection & $4(2.3)$ \\
& IV cannulation & $51(29.5)$ \\
& Finger prick blood sampling & $34(19.7)$ \\
& Assist surgical procedure & $13(7.5)$ \\
& Handling IV sets & $1(0.6)$ \\
& Blood drawing & $33(19.1)$ \\
During which part of the procedure you got NSI & Other & $14(8.1)$ \\
& Inserting needle & $14(8.1)$ \\
& Withdrawing needle & $67(38.7)$ \\
& Recapping & $24(13.9)$ \\
& Transferring to container & $9(5.2)$ \\
& Transporting to sharp bin & $32(18.5)$ \\
& Discarding to sharp bin & $8(4.6)$ \\
& Other & $19(11.0)$ \\
\hline
\end{tabular}

The following Table 6 shows why nursing officers do re-capping after they drew blood from the patient. Needle re-capping was observed in $13.9 \%$ of the affected population. 
Table 6. Reasons for $\mathrm{Re}-$ capping $(\mathrm{n}=24)$

\begin{tabular}{lll}
\hline & Category & $\mathrm{n}(\%)$ \\
\hline Reasons for Needle & prevent blood spill & $5(20.8)$ \\
re-capping & prevent harm to others & $12(50.0)$ \\
& usual practice & $4(16.7)$ \\
& other & $3(12.5)$ \\
& Total & $24(100)$ \\
\hline
\end{tabular}

The Table 7 shows the unit at work when the nursing officers experienced the NSIs. It is observed that some NSIs had occurred when they had been working in other units which were not included in the study as they rotate between units their nursing career. The highest prevalence was observed in Medical wards (78\%) followed by surgical $(23 \%)$ and paediatric wards $(15 \%)$.

Table 7. Prevalence of NSI in relation to unit at work $(\mathrm{N}=173)$

\begin{tabular}{lll}
\hline & Description & $\mathrm{n}(\%)$ \\
\hline & Blood bank & $2(1.2)$ \\
& Chest ward & $2(1.2)$ \\
Unit at work when NSIs experienced & ETU & $12(6.9)$ \\
& Obstetric ward & $16(9.2)$ \\
& Labour room. & $2(1.2)$ \\
& Dermatology clinic & $1(0.6)$ \\
& Medical clinic & $7(4.0)$ \\
& PBU & $5(2.9)$ \\
& Medical ward & $78(45.1)$ \\
& Surgical ward & $23(13.3)$ \\
& Operation theatre & $10(5.8)$ \\
\hline
\end{tabular}

\subsection{Knowledge on Prevention of NSIs}

The Table 8 shows there is a significant difference in the scores for years of experience in group sustain NSI $(\mathrm{M}=13.69, \mathrm{SD}=8.12)$ and no NSIs $(\mathrm{M}=15.56, \mathrm{SD}=9.96)$ conditions; $\mathrm{t}(399)=-2.016, \mathrm{p}=0.044$.

Table 8. The relationship between the years of experience and the exposure to NSI

\begin{tabular}{lcccl}
\hline Description & $\mathrm{n}$ & Mean of years of experience & SD & Statistics \\
\hline $\begin{array}{l}\text { Exposure to NSIs } \\
\text { Yes }\end{array}$ & 173 & 13.69 & 8.12 & $\begin{array}{l}\text { Independent sample t- test } \\
\text { no }\end{array}$ \\
\hline
\end{tabular}

TheTable 9 shows the effect of continuous medical education on experiencing NSIs. Majority of the study subjects had in-service training (58.3\%). There was no significant relationship in experiencing NSIs and participation in in-service training programs $\left(\mathrm{X}^{2}[1, \mathrm{~N}=173]=-0.268, \mathrm{p}=0.592\right)$ and having additional post diploma qualifications $\left(\mathrm{X}^{2}[1, \mathrm{~N}=90]=0.195, \mathrm{p}=0.659\right)$. 
Table 9. The relationship between NSI and having participated in in-service training programs and having additional post diploma qualifications

\begin{tabular}{llll}
\hline & Category & $\mathrm{n}(\%)$ & Statistical test \\
\hline Participation in in-serv. train. $(\mathrm{N}=173)$ & none & $72(41.6)$ & Chi-square test \\
& yes & $101(58.3)$ & value -0.268 \\
& & & $\mathrm{p}=0.592$ \\
\hline Having additional qualifications & Yes & $37(41.1)$ & Chi-square test \\
$(\mathrm{N}=90)$ & no & $53(58.9)$ & value $=0.195$ \\
& & & $\mathrm{p}=0.659$ \\
\hline
\end{tabular}

\subsection{Practice on prevention of NSIs and Response}

The following table shows the practices of nurses when handling sharp objects. $31.6 \%$ of the study participants revealed they re-cap the needle. And practice of bending the needle after used on a patient was observed in $2 \%$ of the population. Needle re-capping was observed in 33 subjects and 159 subjects never used gloves.

Table 10. Practice of re-capping of needles, bending needles and use of gloves during clinical procedures with needle handling $(\mathrm{N}=401)$

\begin{tabular}{lll}
\hline & Description & $\mathrm{n}(\%)$ \\
\hline Prac. of re-capp. needles & Never & $274(68.3)$ \\
& Sometimes & $94(23.4)$ \\
& Always & $33(8.2)$ \\
\hline Practice of bending needles & Never & $393(98)$ \\
& sometimes & $6(1.5)$ \\
& Always & $2(0.5)$ \\
\hline Practice of use of gloves & Always & $128(31.9)$ \\
& Not regularly & $106(26.4)$ \\
& Never & $159(39.7)$ \\
& Only anticipate contamination & $8(2.0)$ \\
\hline
\end{tabular}

Table 11 shows how many nursing officers had taken the government free offered Hepatitis B vaccination. Majority $(64.3 \%)$ had taken the vaccine but rest of the nursing officers had either not taken $(5.5 \%)$ or had incomplete immunization.

Table 11. The Hepatitis B immunization status of the population $(\mathrm{N}=401)$

\begin{tabular}{lll}
\hline & Category & $\mathrm{n}(\%)$ \\
\hline & One dose & $34(8.5)$ \\
& Two doses & $76(19.0)$ \\
Hepatitis B immunization status of the population & Three doses & $258(64.3)$ \\
& No idea & $11(2.7)$ \\
& Not vaccinated & $22(5.5)$ \\
\hline
\end{tabular}

The state of incident reporting and participate in the hospital post exposure procedure is shown in the Table 12 . Only $46.8 \%$ of the study participants who experienced NSIs had reported the incident to the Infection Control Unit. The reasons for under reporting were mainly assumed less risk of transmission of the diseases $(53.5 \%)$ and $33.7 \%$ 
stated the procedure was time consuming. Two nursing officers were not aware of the post exposure infection control procedure for NSIs.

Table 12. Incident reporting and reasons not to report NSIs

\begin{tabular}{lll}
\hline & Category & $\mathrm{n}(\%)$ \\
\hline \multirow{2}{*}{$\begin{array}{ll}\text { Did you participate in the post exposure } \\
\text { procedure }(\mathrm{N}=173)\end{array}$} & Yes & $81(46.8)$ \\
& No idea & $6(3.5)$ \\
\hline \multirow{2}{*}{ What is the reason not to report $(\mathrm{N}=86)$} & Do to less risk & $86(49.7)$ \\
& Due to time consuming & $46(53.5)$ \\
& Not aware of the procedure & $29(33.7)$ \\
& other & $9(10.5)$ \\
\hline
\end{tabular}

\subsection{Factors Associated with NSIs}

The table 13 below shows the association of NSIs and of some of the selected factors age, average number of patients seen per day, average number of working hours per week and average years of work experience. A significant difference in the scores for mean age (of group sustain NSIs $[\mathrm{M}=38.8, \mathrm{SD}=7.9$ and no NSIs $\mathrm{M}=40.9$, $\mathrm{SD}=9.4]$ conditions $\mathrm{t}(399)=-2.438, \mathrm{p}=0.015)$ and the mean years of experience (of group sustain NSIs $[\mathrm{M}=13.69$, $\mathrm{SD}=8.12$ and no NSIs $\mathrm{M}=15.56, \mathrm{SD}=9.96$ ] conditions $\mathrm{t}(399)-2.016, \mathrm{p}=0.44)$ older and more experienced had less number of NSIs. But no significant difference was seen between the average number of working hours and the average patients seen per day.

Table 13. Association of NSI with age, average number of patients seen per day, average number of working hours per week and average years of experience $(\mathrm{N}=401)$

\begin{tabular}{lcccl}
\hline Description & $\mathrm{n}$ & mean & $\mathrm{SD}$ & $\begin{array}{l}\text { Statistical tests } \\
\text { Independent sample } \mathrm{t} \text {-test }\end{array}$ \\
\hline Age & & & & \\
NSI Yes & 173 & 38.8 & 7.9 & $\mathrm{t}=-2.438$ \\
NSI no & 228 & 40.9 & 9.4 & $\mathrm{p}=0.015$ \\
\hline Average no of patients /day & & & & \\
NSI yes & 173 & 32.7 & 27.9 & $\mathrm{t}=-0.299$ \\
NSI no & 228 & 33.5 & 19.4 & $\mathrm{p}=0.765$ \\
\hline Ave. no of working hrs/wk & & & & \\
NSI yes & 173 & 45.8 & 9.5 & $\mathrm{t}=1.273$ \\
NSI no & 228 & 44.5 & 9.5 & $\mathrm{p}=0.204$ \\
\hline Ave. years of experience & & & & \\
NSI yes & 173 & 13.69 & 8.12 & $\mathrm{t}=-2.016$ \\
NSI no & 228 & 15.56 & 9.96 & $\mathrm{p}=0.044$ \\
\hline
\end{tabular}

\section{Discussion}

Nurses were selected in this study because in Sri Lankan hospital set up nurses are more exposed to handling sharps at wards. Three hospitals from different provinces enabled the findings to generalize to a certain extent. The purpose of selecting five routine work units from each hospital was to further analyze the risk associated with the unit at work and to find out the risk associated with routine work schedules giving much wider and much deeper analysis on NSIs. 
In the study sample the prevalence of NSI throughout the career was $43 \%$ (173). This value is relatively better than the previous local and international studies. In Sri Lanka (Vithana et al., 2005), explained in their study that the NSIs give rise to $59 \%$ of injuries caused by sharps. But a cross sectional study done on HCWs at risk of exposure to blood and body fluids of HIV suspected patients (Karawita, Gunathilaka, Hettiarachchi, K.Ariyaratne \& L. Ariyarathne, 2012) in Sri Lanka found prevalence of NSIs was 9.5\% and the prevalence among nursing officers was $14.1 \%$. This study sample was selected purposefully from those health institutions on the basis of having experience in handling HIV suspected patients.

The prevalence of NSIs in a Tertiary care hospital in India revealed $80.1 \%$ (Muralidhar, Sing, Jain, Malhotra \& Bala Manju, 2010) among different staff categories. Nursing officers experienced $11 \%$ and junior, senior and intern medical officers comprised of the main part of the prevalence. This pattern was observed in their study due to handling of patients with regard to blood and body fluids were mainly done by the doctors in Indian hospitals. But Sharma, Rasania, Verma \& Singh, 2010, in their study found that nursing students had high percentage of NSIs $(94.2 \%)$. A cross sectional study done among nursing officers in a public hospital in Tehran resulted a $56.96 \%$ of NSIs during their professional life (Galougahi \& Hassan, 2010). The prevalence rate for at least one NSI in their career was found as 67\% in Pakistan (Habib, Khan, \& Aziz, 2010). A confidential survey done in National Health Service in United Kingdom also revealed a rate of $74 \%$ of NSI prevalence among nursing officers during their career (Elimiyeh et al., 2004). Therefore similar pattern of incidents were noted in both developed and developing countries.

When NSIs were analyzed with time, more than 70\% (124) of the NSIs had occurred during the past three years. Majority had experienced one NSI but more than four NSIs were observed in $4.6 \%$ (8) and $8.1 \%$ (14). When prevalence was analyzed in relation to last year, at least one exposure was seen in $35.3 \%$ (62) of the nursing officers. One nursing officer had experienced more than four NSIs during the year gone. Much higher incidents (63\%) observed in research done by Ebrahami \& khosvari, 2007 in Iran for the past year.

Needle stick injuries when analyzed in relation to unit at work medical wards had the highest frequency of incidences $45.1 \%$ (78) followed by surgical wards $13.3 \%$ (23). These results can be explained as most frequent procedures associated with NSIs IV cannulation $29 \%$ (51) followed by finger prick blood sampling $19.7 \%$ (34), blood drawing 19.1\% (33) and IV injections 13.3\% (23) were mostly performed in medical wards. Muralidhar, et al., 2010 explained in his study in India that the blood drawing was the commonest procedure associated with NSIs but the unit at work was not stated.

Re-capping of used needles was found as the most prevalent and concerned part of the injury causing procedure in most literature (Muralidhar et al., 2010 \& Sharma et al., 2010). This was emphasized in many studies due to having high chance of preventability and not advised in universal precautions. In contrast in this study the most injury causing procedure was revealed as while withdrawing the needle from the patient $38.7 \%$ (67). Second in place was while transporting to the sharp bin $18.5 \%$ (32) and re-capping of needles $13.9 \%(24)$ was the third cause. When the total sample was inquired about needle re-capping $68.3 \%$ (274) of the population never did re-capping. Re-capping as seen as a usual practice in $16.7 \%$ (4) to prevent harm to the others.

There was a significant association between mean ages of the two population groups in relation to exposure to NSI $(\mathrm{p}=0.015)$ being younger age group experiencing more NSIs than the older group. But further analysis is needed due to narrow age gap between the two groups. However this finding provided supportive evidence to the finding that less prevalence of NSIs occur among more experienced nursing officers.

Increase work load and fatigue are contributing factors to errors in judgment and occupational injuries. In agreement Trinkoff, Brown \& Lipscomb, 2007 in her study in United States described that long working hours, working off- shifts and working on week-ends contributes significantly to NSIs and other injuries and illnesses such as musculoskeletal disorders. But in contrast this study revealed there was no significant difference between number of patients attended per day $(p=0.765)$ and mean number of working hours per week $(p=0.204)$ in relation to occurrence of NSIs.

Knowledge was analyzed by working experience, number of in-service training programs attended, additional post diploma qualifications attained, knowledge on universal precautions and general knowledge on diseases transmitted by blood and body fluids.

Knowledge was expected to increase with increase working experience. In agreement with this argument in this study the group which was not experienced NSIs had a higher mean years of working experience and the difference between the two groups was also found to be significant with independent sample t-test $(p=0.044)$. There was no association found between in-service training and exposure to NSIs. Similarly, there was no significant association 
seen between the post diploma qualification holders and experience of NSI when analyzed with chi-square test ( $p$ $=0.659$ ). But this factor needs further analysis in depth with time relationship in acquiring in-service training and the exposure to NSI.

Nearly $80 \%$ of the sample believed their knowledge had to be improved on universal precautions. Majority of the nursing officers admitted the reason for NSI was due to not practicing the knowledge they have on universal precautions and admitted it was their negligence.

The knowledge that main diseases can get transmitted through NSIs revealed not satisfactory. Only 68\% (273) knew that the Hepatitis B has the highest chance of transmission through blood and body fluid contamination through NSIs when compared with HIV and Hepatitis C. More than one fifth of the total population believed 21.2\% (85) HIV infection has the highest chance of transmission and 35 subjects $(8.7 \%)$ admitted they have no idea on the disease transmission.

Poor quality instruments and poor quality working conditions were collectively attributed to $13.9 \%$ (24) injuries. Majority of nursing officers who thought their injury was due to poor quality instruments $7.5 \%$ (13) stated that the syringes they were provided for blood drawing were of poor quality $53.8 \%$ (7) and needed to re-cap to unscrew the needle from the syringe due to tight fitting. Subjects who thought poor working conditions $70 \%$ (7) attributed it to increase work load.

Prevent harm to the others was the main reason to re-cap needles $50 \%$ (12). Similar answers been given in surveillance data in Canadian National Surveillance of Occupational Exposure to HIV. This factor highlights the need to redirect training programs over to changing attitudes and practices rather than giving knowledge.

As a part of the practice response to NSIs were assessed in accordance with status of the Hepatitis B vaccination, immediate basic post exposure management, duties of infection control liaison officer at ward, procedure followed at the infection control unit, ethical considerations of the procedure and reasons to not to participate in the post exposure procedure.

Hepatitis B immunization status was found less satisfactory. Even though the immunization was available to all nursing officers only $64 \%$ had completed the immunization course and twenty two subjects had never given the immunization. Response after the exposure to NSIs was also inadequate. Of the subjects who had not completed the vaccination $46 \%$ (40) had not offered the Hepatitis B immunization. Only four subjects had received Hepatitis B immunization within 24 hours.

At the infection control unit health education had been offered to $84 \%$ (68) of the population. When blood investigations were considered Hepatitis B antibody test was offered only to 49.4\% (40) subjects and HIV antibody test was offered to $81.5 \%$ (66) subjects. Patient's blood was investigated in $88.9 \%$ (72) of the instances. Receiving post exposure prophylaxis was only note in two subjects $(2.5 \%)$. When ethical issues with regard to the procedure were inquired only $37 \%$ (30) of the population agreed the procedure offered the confidentiality. Informed consent was taken from the patient before taking the blood samples in $75.3 \%$ (61) of the instances.

Majority of the nursing officers $49.7 \%$ (86) who experienced NSIs did not report their injury to the infection control unit. The reason was no felt risk 53.5\% (46) and believe that procedure was time consuming $33.7 \%(29)$.

In general post exposure management seemed not satisfactory and there is still more scope for improvement. Providing Hepatitis B immunization in time is also not hundred percent. Confidentiality of the procedure is not always secured. Awareness of the post exposure procedure and reporting still need improvement. Improving in shortcomings of this procedure may ensure more reporting of such injuries.

Selection of the sample ideal would have been multi-stage cluster sampling of DGHs and further within each hospital considering all clinical units handling sharps by nursing officers. But due to time and cost constraints purposive selection of hospitals was done including the selection of five clinical units. Recall bias was seen when data collection on NSI prevalence during life time and further analysis of last NSI. Self -administered questionnaire was given in view of high health literacy among nursing officers aiming at increase response rate, less cost and less time consuming. But more validity and reliability would have been achieved with interviewer administered questionnaire.

\section{Conclusions}

As this study revealed important aspects with regard to prevalence of NSIs among nursing officers as well as their practices following conclusions can be made after interpretation of results.

It is concluded that prevalence of NSIs were still high among nursing population in DGHs in Sri Lanka. Most of the injuries were caused during the procedure of IV cannulation. Further analysis revealed that the most injury 
causing part of the procedure was while withdrawing the needle from the patient.

It further concluded that younger nurses were more exposed to more NSIs while older nurses have shown less NSIs.

In contrary to the common belief that NSIs are more prevalent with increased work load and less training this study shows that having in-service training did not reduce the incidence of NSIs. Similarly with increased work load there was no increase prevalence of NSIs.

It also concluded that knowledge on selected areas on prevention of NSIs was good but the results indicated the practices were poor. Practices of universal precautions were poor and mainly concerned with negligence.

The study also revealed that the post exposure reporting rate needed improvement. Finally the hepatitis B immunization provision must be improved. It is both pre and post exposure coverage is inadequate.

\section{Competing Interests Statement}

The authors declare that they have no competing or potential conflicts of interest regarding the publication of this paper.

\section{References}

Asia Pacific Regional Report. Universal Access. (2011). Achieving universal access: Supporting community sector involvement \& advocacy.

Deussom, R., Jaskiewicz, W., Adams, E., \& Tulenko, K. (2012) Ensuring a Positive Practice Environment: Occupational Safety and Health for Health Worker Productivity. Technical Brief, 4(August 2012).

Deisenhammer, S., Randon, K., Nowak, D., \& Reichert, J. (2012) Needlestick Injuries During Education Period in Nursing Students in Turkey. Procedia: Social and Behavioural Sciences, 46, 3798-3801. https://doi.org/10.1016/j.sbspro.2012.06.149.WCES 2013

Ebrahami, H., \& Khosravi, A. (2007). Needle Stick Injuries among Nurses. J Res Health Sci., 7(2), 56-2.

Elimiyeh, B., Whitaker, I. S., James, M. J., Chahal, C. A. A., Galea, A., \& Alshafi, K. (2004). Needle-stick injuries in the National Health Service: a culture of silence. Journal of the Royal Society of Medicine, 97(7). 326-327. https://doi.org/10.1258/jrsm.97.7.326

Habib, H., Khan, E. A., \& Aziz, A. (2011) Prevalence and Factors Associated with Needle Stick Injuries among Registered Nurses in Public Sector Tertiary Care Hospitals of Pakistan. International Journal of Collaborative Research on Internal Medicine \& Public Health, 3(2).

Galougahi, K., \& Hassan, M. (2010). Evaluation of needle stick injuries among nurses of Khanevadeh hospital in Tehran. Iranian Journal of Nursing and Midwifery Research, 15(4), 172-177.

Karawita, D. A., Gunathilaka, M. P. W., Hettiarachchi, I., Ariyaratne, K. A. M., \& Ariyaratne, L. (2012) The knowledge, practices and the extent of occupational exposure to blood among healthcare workers in Colombo; A cross sectional study. The Sri Lanka Journal of Venereology, 3(1), 23-28.

Lawanga, S. K., \& Lemesho, S. (1991). Sample Size Determination in Health Study: A Practical Manual (pp. 1-3). Geneva: WHO.

Lee, J., \& Bottleman, M. (2005) Needle stick injury in acute care nurses caring for patients with diabetes mellitus: A retrospective study. Curr Med Res Opin., 21(5). 741. https://doi.org/10.1185/030079905X46205

Ministry of Health. Sri Lanka. (2003). Annual Health Bullatin.

Ministry of Health. Sri Lanka. (2011). Health Facility Survey.

Muralidhar, S., Singh, P. K., Jain, R. K., Malhotra, M., \& Bala, M. (2009). Needle stick injuries among health care workers in a tertiary care hospital of India. Indian J Med Res., 131 (March 2010), 405-410.

Peuss-Ustun, A. Rapiti, E. \& Hutin, Y. (2005) Estimation of the global burden of disease attributable to contaminated sharps injuries among health-care workers. Am J Ind Med, 48(6), 482-90. https://doi.org/10.1002/ajim.20230

Saia, M., Hofmann, F., Sharman, J., Abiteboul, D., Campins, M., Burkowitz, J., Choe, Y., \& Kavanagh, S. (2010) Needlestick Injuries: Incidence and Cost in the United States, United Kingdom, Germany, France, Italy and Spain. Biomedicine International, 1, 41-49.

Sharma, R., Rasania, S. K., Verma, A., \& Singh, S. (2010). Study of prevalence and Response to Needle Stick 
Injuries among Health Care Workers in a tertiary Care Hospital in Delhi, India. Indian Journal of Community Medicine, 35(1), 74-77. https://doi.org/10.4103/0970-0218.62565

Trinkoff, A. M. Le, R., Brown, J. G., \& Lipscomb, J. (2007). Work schedule, Needle Use, and Needle stick injuries among Registered nurses. Infect Control Hosp Epidemol., $28(2$ Feb 2007), 156-164. https://doi.org/10.1086/510785

United States. Centers for Disease Control and Prevention. (2003). Bloodborne Infectious Diseases: HIV/AIDS, Hepatitis B, Hepatitis C.

United State. Labour Department. (2001). Federal Needlestick Safety and Prevention Law.

Vithana, V. H., Weerakkody, M. I., Pallewela, V. H., Karunanayaka, P., Senarath, U., \& Sheriff, M. H. R. (2005). Management of occupational exposure to blood and body fluids among health care workers in the National Hospital of Sri Lanka: an audit of practice. Sri Lanka Medical Association - 118th Anniversary Academic Sessions.

Wicker, S., Jung, J., Allwin, R., Gottschalk, R., \& Rabenau, H. F. (2008) Prevalence and Prevention of Needlestick Injuries among Health Care Workers in a German University Hospital. Int Arch Occup Environ Health, 81, 347. https://doi.org/10.1007/s00420-007-0219-7

World Health Organization. (1994). Declaration of occupational health for all.

\section{Copyrights}

Copyright for this article is retained by the author(s), with first publication rights granted to the journal.

This is an open-access article distributed under the terms and conditions of the Creative Commons Attribution license (http://creativecommons.org/licenses/by/4.0/). 